\title{
Human Heat stress risk prediction in the Brazilian semiarid Region based on the Wet-Bulb Globe Temperature
}

\section{BEATRIZ FÁTIMA A. DE OLIVEIRA ${ }^{1}$, ISMAEL HENRIQUE SILVEIRA ${ }^{2}$, RENATO C. FEITOSA ${ }^{1}$, MARCO AURÉLIO P. HORTA ${ }^{3}$, WASHINGTON L. JUNGER ${ }^{2}$ and SANDRA HACON ${ }^{1}$}

\author{
${ }^{1}$ National School of Public Health, Oswaldo Cruz Foundation, 1480 Leopoldo \\ Bulhões St., Manguinhos, 20160-030 Rio de Janeiro, RJ, Brazil \\ ${ }^{2}$ Institute of Social Medicine, State University of Rio de Janeiro, 524 São Francisco \\ Xavier St., Maracanã, 20550-900 Rio de Janeiro, RJ, Brazil \\ ${ }^{3}$ Oswaldo Cruz Institute, Oswaldo Cruz Foundation, 4365 Brasil Ave., Manguinhos, 21040-900 Rio de Janeiro, RJ, Brazil \\ Manuscript received on July 25, 2018; accepted for publication on October 17, 2018
}

\begin{abstract}
How to cite: OLIVEIRA BFA, SILVEIRA IH, FEITOSA RC, HORTA MAP, JUNGER WL AND HACON S. 2019. Human Heat stress risk prediction in the Brazilian semiarid Region based on the Wet-Bulb Globe Temperature. An Acad Bras Cienc 91: e20180748. DOI 10.1590/0001-3765201920180748.
\end{abstract}

\begin{abstract}
Objective: the aim of this study is to map thermal stress risks for human health at the São Francisco River Basin (SFRB) in the Semiarid region, for climatic scenarios RCP 4.5 and 8.5. Methods: The heat stress conditions were defined by the Wet Bulb Globe Temperature (WBGT) indicator and by the average number of annual days in which the WBGT values exceeded the 90th percentile of the reference period. The WBGT was estimated for the climate scenarios RCP 4.5 (intermediate) and 8.5 (pessimistic) for the period 2011-2090 comparing to the period of reference (1961-2005). Results: The projections show that for the pessimistic scenario practically all municipalities of the SFRB region can reach values of WBGT that indicate a high risk for heat stress in the period 2071-2099. For this same scenario and period, the municipalities of the Lower and Under-average regions may present values of WBGT above the 90th percentile of the reference period in more than $90 \%$ of the days/year. Conclusions: These results show that, if the emission of greenhouse gases continues in the present proportions, some municipalities of the SFRB region may present a high risk for heat stress affecting the work capacity and the practice of physical exercises.
\end{abstract}

Key words: Climate change, heat stress, health impacts, Wet Bulb Globe Temperature.

\section{INTRODUCTION}

Climate change is among the world's major environmental problems, and there is a scientific consensus that its impacts can already be observed in many regions, especially due to the increase in extreme events such as floods, prolonged droughts

Correspondence to: Beatriz Fátima Alves de Oliveira

E-mail: beatrizenf@gmail.com

ORCid: https://orcid.org/0000-0003-0103-3309 and heat waves (IPCC 2013). In recent decades, heat waves were responsible for an excess of 70,000 deaths in Europe in 2003 and 15,000 deaths in Russia in 2010 (Robine et al. 2008, Matsueda 2011).

Much of the heat-related excess morbidity and mortality is associated with the organism's resilience inability to maintain internal body temperature at homeostasis. In certain situations, exposure to environmental conditions exceeds the theoretical limits of human tolerance, while 
heat gain exceeds loss conditions, favoring the occurrence of thermal stress and, consequently, increases in body temperature (Havenith and Fiala 2015). Increases around $3^{\circ} \mathrm{C}$ above so-called normothermia, the normal temperature range of the human body, can lead to an overload of the cardiovascular system, damage to physiological systems and even a collapse of vital functions, especially in vulnerable groups such as children, the elderly, pregnant women and patients with preexisting diseases (Coffel et al. 2018).

In the last decades, over 160 different thermal stress indices have been developed to assess heat stress on the human body (Havenith and Fiala 2015). Among the various proposed indices, the Wet-Bulb Globe Temperature (WBGT) (Yaglou and Minard 1957 ) is one of the most popular, widely applied in military training, sports medicine and work safety (Stott et al. 2004, Budd 2008, Rahmstorf and Coumoum 2011, Dunne at al. 2013). Its estimation allows for the establishment of an absolute limit to metabolic heat transfer based on the laws of physics (Sherwood and Huber 2010), combining temperature, relative humidity, wind speed and solar radiation values (Yaglou and Minard 1957). The baseline values for these parameters depend on other factors, such as metabolic activity, dressing and acclimatization factors, e.g., human outdoor exposure to WBGT values above $28^{\circ} \mathrm{C}$ can increase heat stress under conditions of intense and prolonged physical activity, whereas values above $35^{\circ} \mathrm{C}$ are considered hazardous, regardless of effort (ISO 7243 1989).

Recently, the WBGT has been used to evaluate dangerous combinations between heat and relative air humidity for human health (Sherwood and Huber 2010, Pal and Eltahir 2016, Coffel et al. 2018). From a climate change perspective, human exposure to WBGT above $35^{\circ} \mathrm{C}$ can be achieved in countries of the Middle East and India (Pal and Eltahir 2016, Im et al. 2017) and thermal stress conditions may exceed one million people/day/year by 2080 (Coffel et al. 2018). In Brazil, between 1999 and 2008 the annual WBGT peak was around $25-30^{\circ} \mathrm{C}$, and future estimates predict values close to $35^{\circ} \mathrm{C}$ for the Northern region by the end of the century in a high emission scenario, posing risks for human health (Sherwood and Huber 2010).

Regardless of estimated WBGT values at or not approaching $35^{\circ} \mathrm{C}$, projections indicate that thermal stress will impact several sectors, such as agriculture, energy demand, labor activities, emergency services and leisure activities. The risk magnitude for human health of these impacts should be more pronounced in places with latent social, economic and environmental vulnerability conditions, such as in the Brazilian North and Northeast regions. In this context, the aim of this study is to map thermal stress risks for human health at the São Francisco River Basin (SFRB) in the Semiarid region, for climatic scenarios RCP 4.5 and 8.5 .

\section{MATERIALS AND METHODS}

\section{STUDY SITE}

Brazilian Semiarid region is characterized by a social and environmental vulnerability (hydric, sanitation, poor soil), is occupied by approximately 24 million people and it has been designated as the most vulnerable populated dry region in Brazil (Rêgo 2012). It is characterized by irregularity in rainfall distribution, shallow and rocky soils with low water storage capacity that affects subsistence crops and consequently affecting family-run agriculture businesses (Alvalá et al. 2017). The São Francisco River (SFR) is the longest river that runs entirely in Brazilian territory and the fourth longest in South America (after Amazon, Paraná and Madeira River). With 2,914 kilometers in length, the SFR originates in the State of Minas Gerais, running north until reaching the Atlantic Ocean. It is an important river for Brazil, named "the national integration river", as it unites several 
regions of the country, in particular the Southeast with the Northeast. As part of the Brazilian semiarid, the São Francisco River Basin (SFRB) is a hydrographic region covering a drainage area of $641,000 \mathrm{~km}^{2}$ (7.5\% of Brazilian territory). This region comprises 507 cities in seven Brazilian States (Bahia, Minas Gerais, Pernambuco, Alagoas, Sergipe, Goiás and the Federal District). The SFRB covers the following Brazilian biomes: Atlantic Rainforest, in the state of Minas Gerais, Brazilian Savanna known as Cerrado (extended between Minas Gerais and Bahia) and Caatinga, in the State of Bahia. The climate is a transition between a humid and an arid tropical climate, with an average temperature of $27^{\circ} \mathrm{C}$, a rainy period between November and January and a dry season between June and August. With an estimated average flow rate of $3000 \mathrm{~m}^{3} / \mathrm{s}$, many losses in the system occur due to high evapotranspiration (A Bacia 2018).

Due to its territorial dimension and for planning purposes, the SFRB is subdivided into 4 regions, high $S F R$, upper middle $S F R$, lower middle $S F R$ and low SFR, according to river direction and altitude variation (A Bacia 2018) (Figure 1). The SFRB population in 2010 was of 18,224,640 inhabitants, with a child population of $25 \%$ (IBGE 2010). The highest demographic concentration is located at the high and upper middle SFR which concentrate respectively, $57 \%$ and $18 \%$ of the population. This concentration occurs in part due to the presence of the Metropolitan Region of Belo Horizonte and the Federal District. According to the Water Resources Plan for SFRB 2016-2025, socioeconomic differences among these regions is clear, with a higher Human Development Index (HDI) for the high SFR region (Belo Horizonte city accounts for 0.810$)$. In contrast, cities located in the middle and low SFR present values lower than 0.700 , with the lowest values observed for Inhapi $(\mathrm{AL})$, Olivença (AL) and Manari (PE).

\section{WET BULB TEMPERATURE ESTIMATE APPROACH}

In this study, the identification of thermal stress risk areas in SFRB municipalities was carried out using the WBGT thermal stress indicator. This indicator measures human exposure to heat that implies in thermal stress and, therefore, potential risks to human health. However, one must take into account that thermal stress effect variations may, to some extent, be attributable to complex interactions between exposure conditions, task characteristics, and individual factors that include, biological and social vulnerabilities (Havenith and Fiala 2015).

\section{STUDY DESIGN}

This is an ecological pilot study to identify thermal stress risk areas for human health at the São Francisco River Basin using as the maximum WBGT as an indicator, estimated from the climatic Eta-HadGEM2-ES model simulations according to IPCC climatic scenarios RCP 4.5 and 8.5 for the timeframes 2011-2040, 2041-2070 and 2071-2099 (Chou et al. 2014a, b).

The identification of thermal stress risk areas was performed under two approaches: 1) Projection of the maximum WBGT for RCP scenarios 4.5 and 8.5 comparing the average WBGT values of timeframes 2011 -2040, 2041 - 2070 and 2071-2099 in relation to the reference period (1961 - 2005); 2) Projection of the number of days during year in which the maximum WBGT values exceeded the $90^{\text {th }}$ percentile values of the reference period (19612005) for each timeframe.

\section{CLIMATE SCENARIOS}

A mapping of thermal stress risk areas for human health was performed for the SFRB region using the Representative Concentration Pathways (RCP), which are $\mathrm{CO}_{2}$-based climate scenarios, according to four different levels of radiative forcing, in $\mathrm{W} / \mathrm{m}^{2}$, until the year 2100 (IPCC 2013). Although RCPs encompass four emission scenarios, the following 


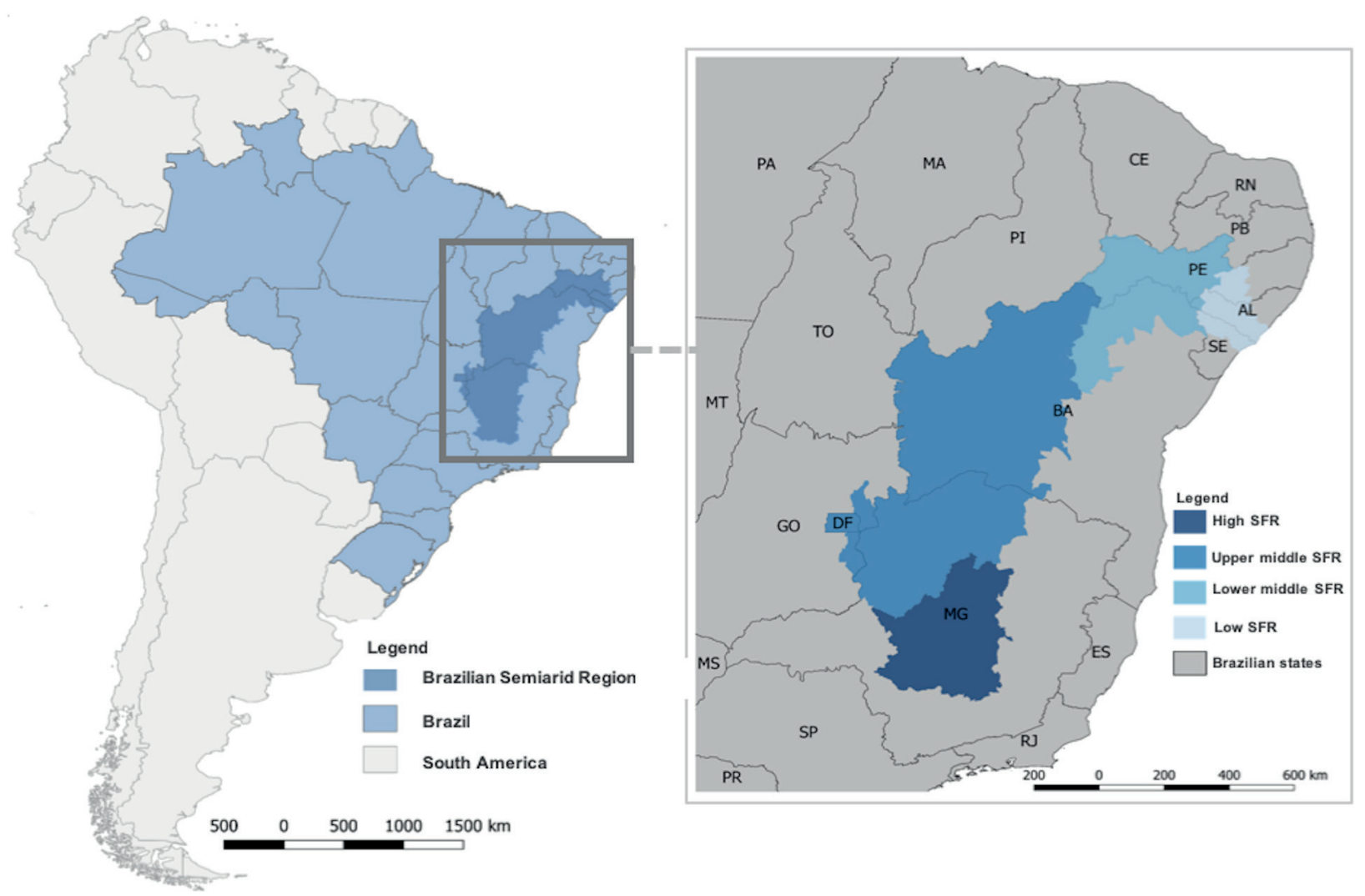

Figure 1 - Geographical location of the San Francisco Basin region.

scenarios were applied herein: 1) RCP 4.5, which represents an intermediate scenario with radioactive forcing stabilization due to the implementation of limited efforts to control $\mathrm{CO}_{2}$ emissions and; 2) RCP 8.5, that corresponds to a high emission scenario, due to large population growth and low technological mitigation levels, with continuously increasing radioactive forcing after 2100 , i.e., the worst possible scenario, with the total absence of $\mathrm{CO}_{2}$ control measures (IPCC 2013).

\section{WET BULB GLOBE TEMPERATURE ESTIMATES}

The equation used to calculate the maximum WBGT for human exposure in outdoor environments is displayed below:

$$
\mathrm{WBGT}=0.7 \mathrm{Tw}+0.2 \mathrm{Tg}+0.1 \mathrm{Ta}
$$

Where: Tw represents the natural wet bulb temperature of the wet bulb, Tg is the temperature of the black globe and $\mathrm{Ta}$ is the air temperature (Yaglou and Minard 1957). Tw and Tg were estimated using data for maximum temperature, relative air humidity, wind speed and radiation, applying the method developed by Liljegren et al. (2008) and recommended by Lemke and Kjellstrom (2012). The methodology used to calculate Tw and $\mathrm{Tg}$ was summarized and presented in the Appendix.

The thermal stress risk groups were based on values established for physical activities in children, a group considered vulnerable to climatic variations. Reference values established by the Sports Medicine and Physical Fitness Committee of the American Academy of Pediatrics (2000) were used. The groups were defined as: 1) Low risk - maximum WBGT values $<24^{\circ} \mathrm{C}$, where all physical activities are allowed; 2) Moderate risk - maximum WBGT values between $24^{\circ} \mathrm{C}$ and $25.9^{\circ} \mathrm{C}$, with indications of physical exercise 
accompanied by long periods of rest and water intake every 15 minutes; 3) High risk - maximum WBGT values between $26^{\circ} \mathrm{C}$ and $29^{\circ} \mathrm{C}$, with indications of discontinuation of physical activity of non-acclimated persons or persons with preexisting health conditions; 4) Extreme risk maximum WBGT values $>29^{\circ} \mathrm{C}$ with interruption of all physical activities and risk to human health. These reference or tolerance values are similar to the permitted limits of labor scale (work/rest) for intense occupational activities (ISO 7243 1989) and international sports training (IAAF 2013). However, the children reference scenario was applied because it is the most conservative exposure condition. In addition to WBGT projections for human health, this study also applied the projection of the mean number and percentage of days in the year in which the maximum WBGT values exceeded the $90^{\text {th }}$ percentile during the reference period (1961-2005) as a thermal stress indicator. This percentage was calculated using the standard Regionalized Climatic Model Eta-HadGEM2-ES calendar, comprising 360 days.

\section{SOURCE AND DATA OPERATION}

The climatic variables were extracted from the Eta-HadGEM2-ES Regionalized Climatic Model provided by the Brazilian Space Research Institute (INPE), at a $1,875^{\circ} \times 1,250^{\circ}$ resolution, for two climatic scenarios RCP 4.5 and 8.5 (Chou et al. 2014a, b). In order to calculate the WBGT, the following activities were carried out: 1) the download of daily data for dew point, maximum temperature, wind speed and short wave solar radiation of the Eta-HadGEM2-ES model from 1961 to 2099 and for the RCP 4.5 and 8.5 scenarios. 2) conversion of BIN format data to NetCDF; 3) extraction of each variable from the NetCDF files and, consequently, calculation of the WBGT indicator for each grid-cells; 4) WBGT estimation for the municipalities, corresponding to the weighted average of the pixel values, according to the proportion of the pixel covered by the municipality. Excluding the download phase, all other phases were processed using the Climate Data Operators (CDO) (Max-PlanckInstitut für Meteorologie 2017) and R (version 3.4.4) software (R Core Team 2017). For each grid-cell we estimated the maximum WBGT and the number of days in which the maximum WBGT exceeded the 90th percentile of the reference period. All indicators were aggregated by municipalities using weighted average values of maximum WBGT within the polygon. In order to estimate the trend, the municipalities maximum WBGT average was used to calculate the maximum WBGT average for SFRB every 10 years.

\section{DATA PRESENTATION AND STATISTICAL ANALYSES}

The analyses carried out in this study were mainly descriptive, with the presentation of the temporal trajectories of the maximum WBGT according to the RCP 4.5 and 8.5 climatic scenarios. The thermal stress risk areas were presented using thematic maps comparing the reference period with the 2011-2040, 2041-2070 and 2071-2099 timeframes. The projections of the maximum WBGT and the percentage of the average number of days/year intervals that exceeded the $90^{\text {th }}$ percentile of the reference period were graphically presented every 10 years for each evaluated scenario, considering the period from 1961 to 2099. In addition, distributions of the maximum WBGT values for the warmest month of the year in the evaluated timeframes were presented according to the SFRB regions and climatic scenarios. The linear trend of the increase of the maximum WBGT values for each semiarid region was estimated using ordinary linear regression (OLR) models, according to the climatic scenarios. The analyses were performed using the R software (version 3.4.4) (R Core Team 
2017) and the cartographic manipulation was carried out with QGIS software (version 2.18.15) (QGIS Development Team 2016).

\section{RESULTS}

During the reference period (1961-2005), the mean maximum WBGT estimates for the SFRB region ranged from $16^{\circ} \mathrm{C}$ to $26^{\circ} \mathrm{C}$, within the low and moderate risk categories for human exposure. From the perspective of the trajectory of the maximum WBGT according to the RCP 4.5 and 8.5 climatic scenarios, an increasing trend was observed throughout the 1960's to 2090, for both scenarios, with respective WBGT increases of $2{ }^{\circ} \mathrm{C}$ and $4{ }^{\circ} \mathrm{C}$ for the end of the century. For the RCP 8.5 scenario, a $0.038^{\circ} \mathrm{C}$ increase in the WBGT was estimated for each decade from 2010 up to 2090 . In relation to the percentage of days presenting WBGT values above the reference period P90, the percentage increase of this indicator from 2070 to 2099 was from 24 days to 200 for the RCP 4.5 scenario and from 24 to 300 for the RCP 8.5 scenario, representing $6 \%$ to $55 \%$ and $6 \%$ to $83 \%$ increases, respectively (Figure 2).

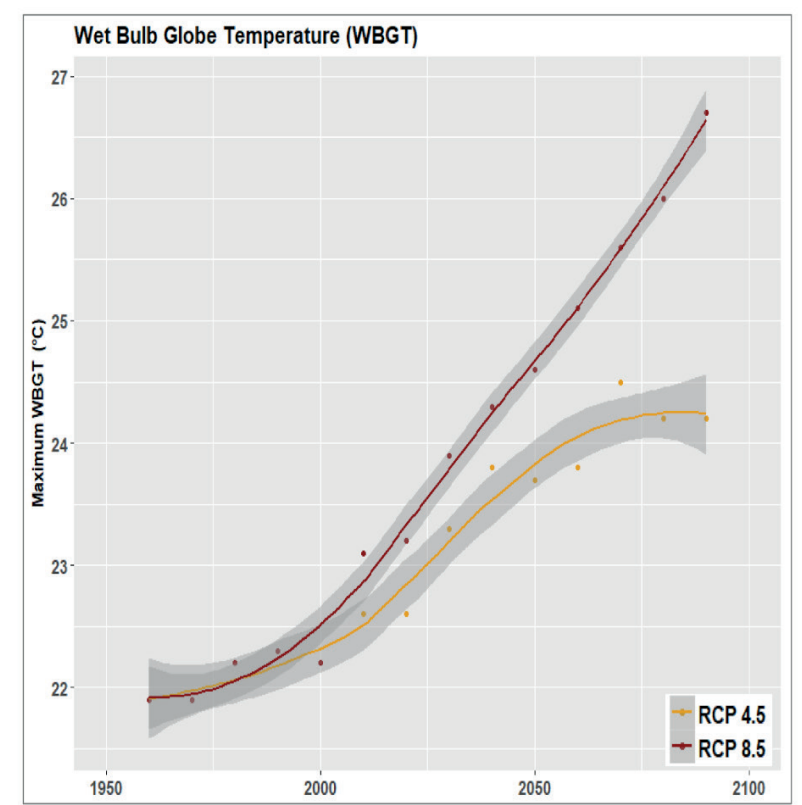

Increased WBGT estimates for the RCP 4.5 scenario were observed for the lower middle and low SFR municipalities over the three assessed periods, especially for the 2071-2090 timeframe, with several municipalities presenting high risk thermal stress areas concerning human health. For the RCP 8.5 scenario, from 2071 to 2099 , excluding some high SFR region areas, every studied region might present a high risk for thermal stress (Figure 3 ). When evaluating the percentage of days per year that exceeded the $90^{\text {th }}$ percentile of the reference period, municipalities located in lower middle and low SFR could experience this condition for over $90 \%$ of the days/year, if greenhouse gas emissions continue at their current rates and the worst-case scenario (RCP 8.5) is achieved (Figure 4).

The distribution of the maximum WBGT daily values for the warmest month of the reference period according to the BHFS regions is displayed in Figure 5. For the low, lower middle and upper middle SFR regions, the month with the highest average WBGT is March, while November presented the highest average WBGT at the high SFR, indicating the worse thermal exposure period

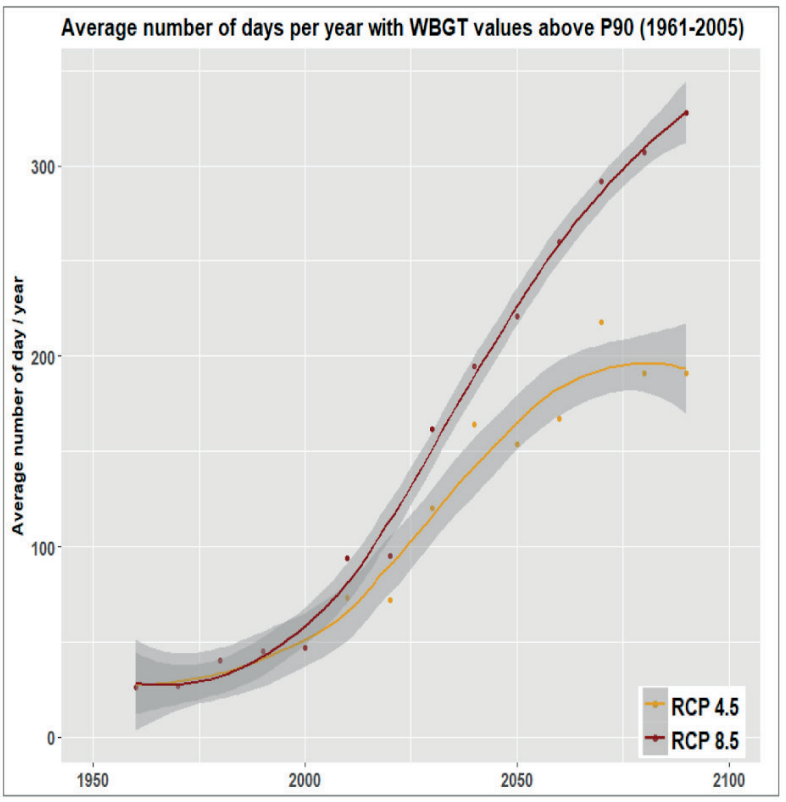

Figure 2 - Projections of the maximum wet bulb globe temperature (WBGT) and the average number of days in which the maximum WBGT exceeded the 90th percentile of the reference period (1961-2005). 

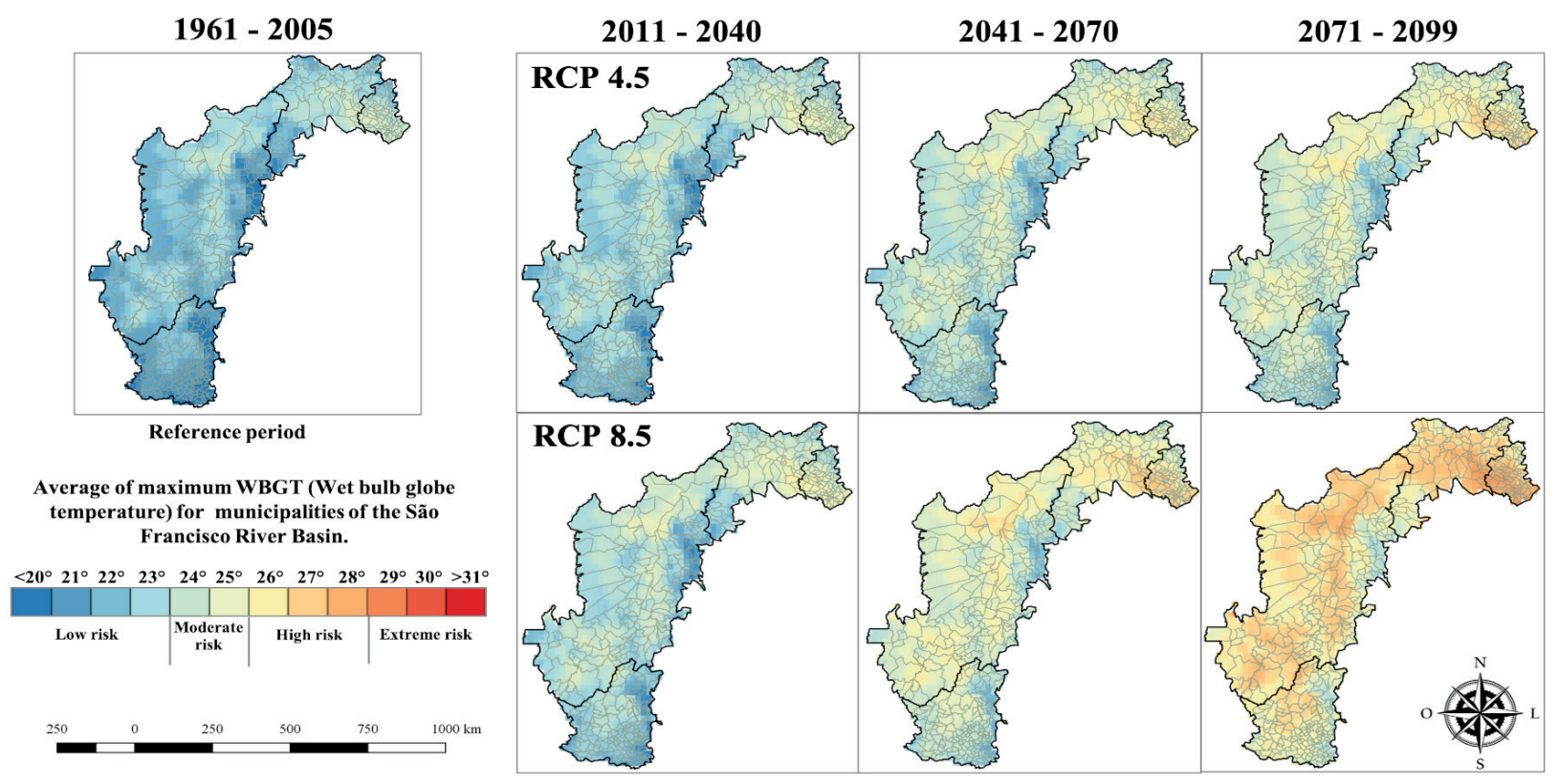

Figure 3 - Projections of the maximum wet bulb globe temperature (WBGT) indicator for the climate scenarios RCP 4.5 and 8.5 for the time windows 2011-2040, 2041-2071 and 2071-2099, comparing to the reference period (1961-2005).
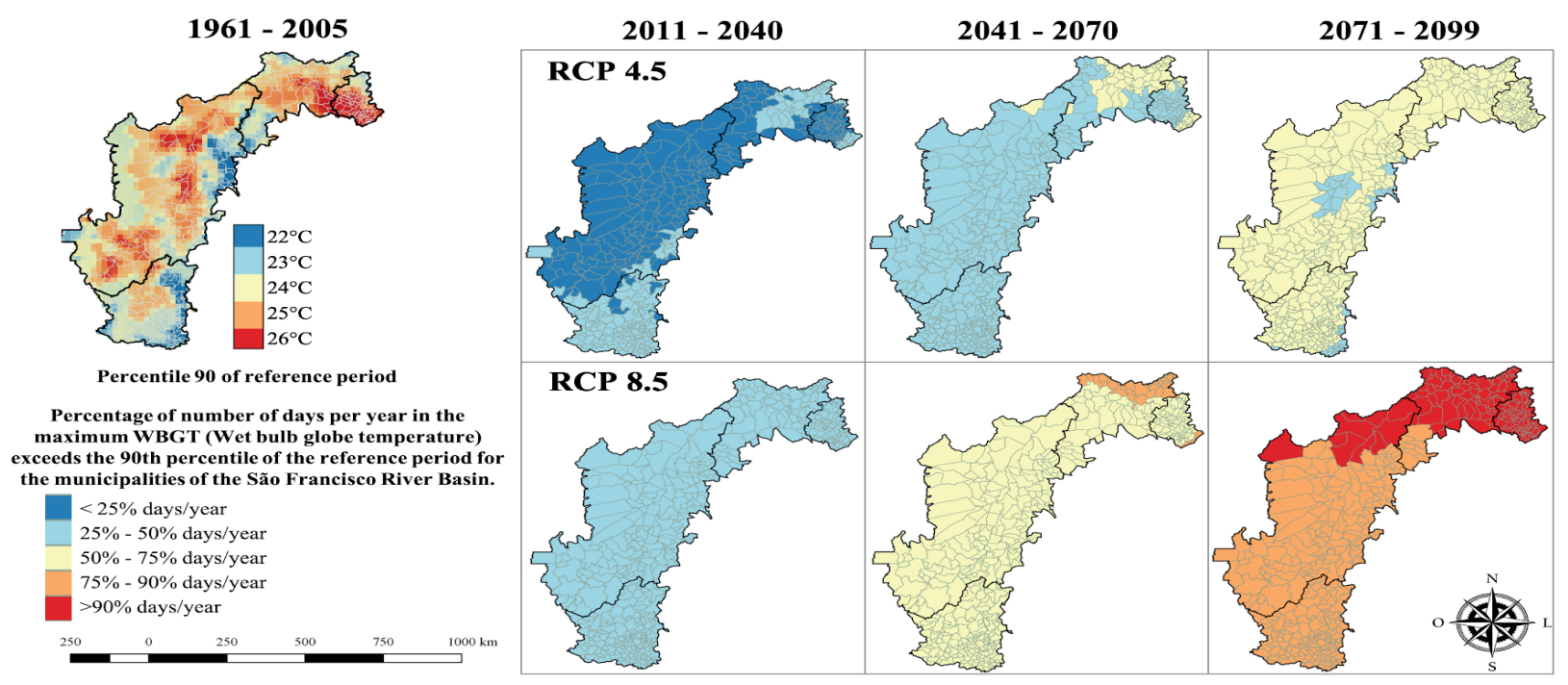

Figure 4 - Projections of the average number of days in which the maximum WBGT exceeded the 90th percentile of the reference period (1961-2005) for the climate scenarios RCP 4.5 and 8.5 and time windows 2011-2040, 2041-2071 and 2071-2099.

for human health. When comparing the maximum WBGT daily values, an increasing trend for this indicator was observed for both the RCP 4.5 and 8.5 scenarios, with different thermal stress risk levels between SFRB regions. Regardless of the climatic scenario, months identified as more thermally stressful during the reference period tend to accentuate thermal stress conditions during the assessed periods.

Among the SFRB regions, low SFR may present over $50 \%$ of the maximum WBGT daily values in March within the limits established as high thermal stress risk in the next 30 years, regardless of the greenhouse effect scenarios. This condition 
may be aggravated at the end of the century for the high emission scenario, where approximately $50 \%$ in March may present thermal stress conditions considered as of extreme risk for human health (Figure 5).

\section{DISCUSSION}

The results suggest that the SFRB region may present high heat stress risks for human health at the end of the century for the high greenhouse gas emission scenario based on WBGT estimates. An increasing trend for WBGT values and the average number of warm days was observed over the evaluated period (1960s to 2090s), indicating an increase in the frequency and intensity of thermal stress conditions in the coming decades, especially in municipalities located in the low and lower middle SFR regions.

The expected WBGT changes were spatially uniform and similar to those projected by global models, with an average increase of approximately $2^{\circ} \mathrm{C}$ for the RCP 4.5 scenario and $4^{\circ} \mathrm{C}$ for the RCP 8.5 scenario at the end of the century. $\mathrm{A} 4^{\circ} \mathrm{C}$ rise in the WBGT in the 2090s, if the RCP 8.5 scenario materializes, may be sufficient to establish small zones or risk areas where the metabolic heat dissipation would become limiting due to external thermal conditions. Even if we control emissions to follow RCP 4.5, municipalities at the low and lower middle SFR would present high thermal stress risks for human health. It is worth mentioning that cities in these regions present high socioeconomic vulnerability, with HDI values of less than 0.700 (Plano de Recursos Hídricos da Bacia Hidrográfica do Rio São Francisco 2015), which could influence the adaptation of this population to thermal stress conditions.

With regard to the projections of the average number of days per year that exceeded the $90^{\text {th }}$ percentile of the reference period, 180-270 days per year of values above those established as reference throughout the region were projected from 2040 to 2070 in the RCP 8.5 scenario. These results suggest clear changes in people's environmental exposure time to unfavorable thermal conditions, where at least $50 \%$ of the year would be above $90^{\text {th }}$ percentile historical values (ranging from $21.8^{\circ} \mathrm{C}$ to $27.2^{\circ} \mathrm{C}$ ), including high health risks values for the region's population. These results are extremely relevant for the strategic planning of the health sector, since exposure duration is essential for the determination of health impacts and subsequent interventions.

The mean maximum WGBT values projected for SFRB regions considering the RCP 4.5 and 8.5 and the 2071-2099 period were, respectively, $23.6^{\circ} \mathrm{C}$ and $25^{\circ} \mathrm{C}$ for high SFR, $24^{\circ} \mathrm{C}$ and $26^{\circ} \mathrm{C}$ for upper middle SFRB, $24.8^{\circ} \mathrm{C}$ and $26.6^{\circ} \mathrm{C}$ for lower middle SFRB and $26^{\circ} \mathrm{C}$ and $27.5^{\circ} \mathrm{C}$ for low SFRB area (highest values peaked $30.2^{\circ} \mathrm{C}$ and $32^{\circ} \mathrm{C}$ ). These values, especially in the warmest scenario, are considered of concern from a public health point of view, especially at the low and lower middle SFR, since they indicate high thermal stress risk, affecting the most vulnerable population groups, the practice of physical exercises in children (American Academy of Pediatrics 2000) and high-performance athletes (IAAF 2013, Nassis et al. 2015) and unacclimated heavy labor activities (ISO 7243 1989, Kjellstrom et al. 2009), including as farmers and construction workers.

Considering the different indicators for assessing adaptation limits, WBGT evaluates heat stress according to the levels of clothing, activity, and acclimatization and the wet bulb temperature tends to establish a clear thermodynamic capacity of the body heat dissipation (Sherwood and Huber 2010, Pal and Eltahir 2016). There are three versions of the wet bulb temperature; and in WBGT formulation, the natural wet bulb temperature has an overall relevance of $70 \%$ when compared to the other parameters of the equation combining air temperature and humidity influenced by heat radiation and wind speed was used by Liljegren et 

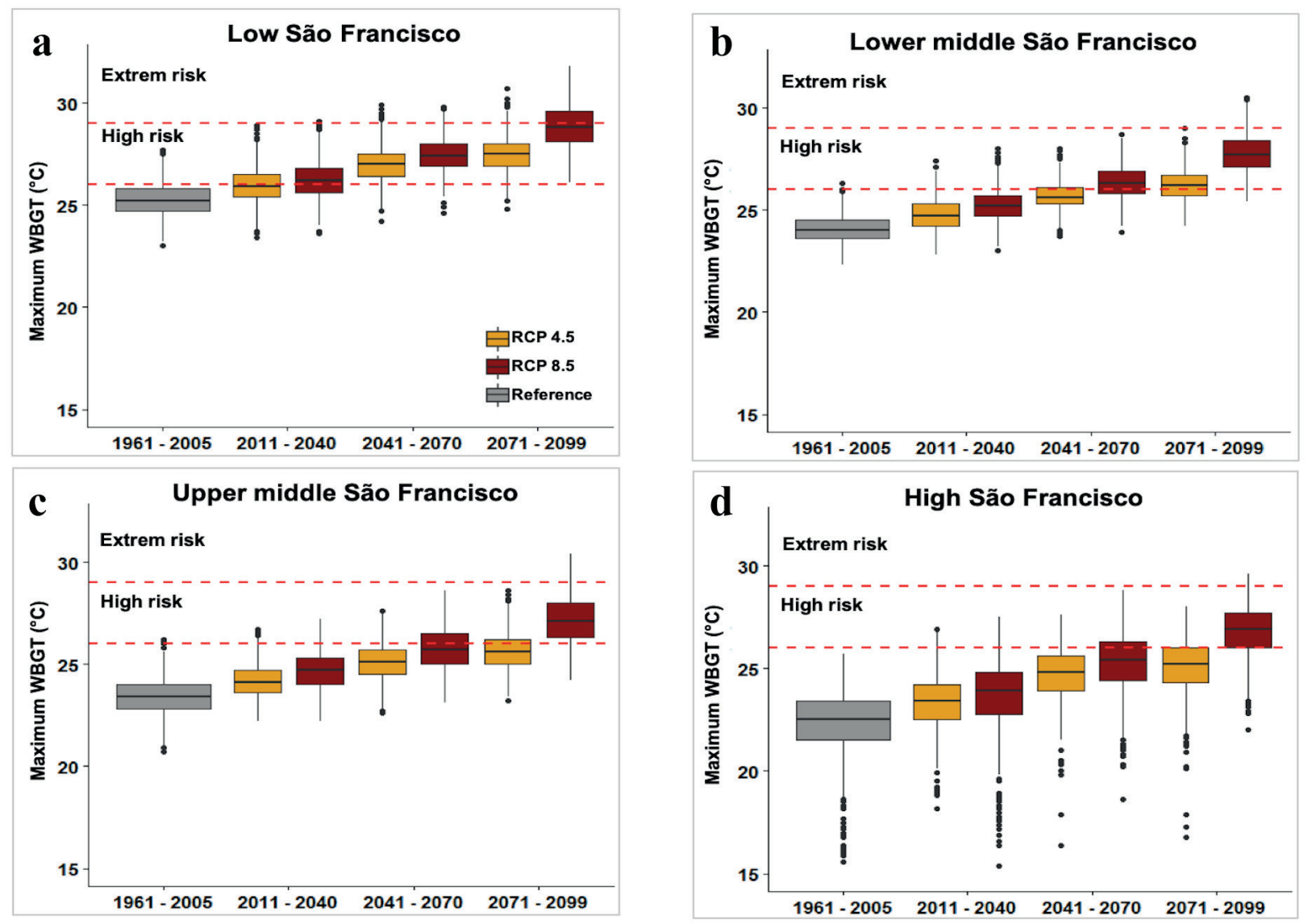

Figure 5 - The distribution of the daily values of the maximum WBGT for the warmest month of the reference period for the climate scenarios RCP 4.5 and 8.5 in the reference period (1961-2005) and the time windows 2011-2040, 2041-2071 and 20712099, in (a) Low, (b) Lower Middle, (c) Upper Middle and (d) High San Francisco.

al. (2008). In the study carried out by Sherwood and Huber (2010), disregarding the effects of radiation, the wet bulb temperature was estimated only in terms of air temperature, humidity, and pressure.

The wet bulb temperature values around $35^{\circ} \mathrm{C}$ may indicate the limit of human tolerance to thermal stress and these values have not been recorded in the current climate conditions (Schär 2016), for instance, maximum values of $31{ }^{\circ} \mathrm{C}$ were observed in India and Brazilian Amazon in 2012 (Sherwood and Huber 2010). The imbalance between production and heat loss leads to serious risks of mental fatigue, physical depletion, dehydration and cardiovascular impairment, resulting in body collapse and death (Sherwood and Huber 2010, Pal and Eltahir 2016).
In Brazil, the WBGT was evaluated during the 2014 Fifa World Cup to assess heat stress effects on high-performance sports (Nassis et al. 2015). The results indicated that $25 \%$ of the games were performed under high thermal stress values (between 28 and $30^{\circ} \mathrm{C}$ ), and at least 2 games showed peaks between $30^{\circ}$ and $32^{\circ} \mathrm{C}$ and above $32^{\circ} \mathrm{C}$. In 2014, the days with the worst WBGT values were negatively correlated to the athletic performance of some players. Thermal stress conditions in sport events such as the summer Olympic games may indicate how global warming could restrict the intense physical undertaken outdoors (Smith et al. 2016).

The discussion on the establishment of temperature limits or WGBT tolerance is still 
permeated by uncertainties, since these limits are notoriously sensitive to several behavioral and cultural factors that influence long term physiological adaptability (IPCC 2013, Bobb et al. 2014). Thus, health outcome effects attributable to heat, such as mortality and hospital admissions, may increase even under non-extreme conditions. Therefore, the expected impacts of thermal stress on human health will depend on the interaction of a set of factors including the severity of extreme thermal conditions, the frequency of these events and the biological and social vulnerability of exposed populations. Among different age groups, children and the elderly are extremely vulnerable to thermal stress conditions, due to their limited capacity to maintain body temperature and greater dehydration risk (Gomes et al. 2013, Kenny et al. 2010). Children present a greater proportion of body surface area in relation to weight, causing greater heat gain from the environment on hot days and greater heat loss on cold days. In addition, this group produces greater metabolic heat per unit of body mass during exercise and displays less transpiration capacity compared to adults (Haymes et al. 1975, Bar-Or, 1989). In the elderly, thermoregulation capacity is altered by decreased cellular metabolism and skin changes (Kenney et al. 1997, Inbar et al. 2004, Kenny et al. 2010).

Regarding worker health, several studies have reported negative exposure effects of extreme thermal conditions on the work capacity of several areas of the economy, especially those considered heavy activities (Nassis et al. 2015, Venugopal et al. 2015, Ioannou et al. 2017). In Brazil, thermal overload was suggested as a triggering factor in the death of 14 sugarcane workers in the state of São Paulo and, in $50 \%$ of the cases, the temperatures recorded on the days the workers died were higher than $27^{\circ} \mathrm{C}$ (Bitencourt et al. 2012). In the São Francisco river region, occupational exposure to thermal stress may be a future concern, especially in the low and lower middle SFR municipalities, where $50 \%$ and $40 \%$, respectively, of occupations by type of activity are in agriculture, livestock, forestry, fishing and aquaculture (Plano de Recursos Hídricos da Bacia Hidrográfica do Rio São Francisco 2015).

In general, it is suggested that physiological resilience or responsiveness due to heat exposure occurs more easily in low relative humidity areas, since the evaporation rate is significantly lower in hot humid areas (Belding and Hatch 1955). However, it is noteworthy that, even with low relative humidity records, very hot places with long solar radiation hours, as in the Brazilian semiarid region, can lead to thermal stress. Under such circumstances, heat transfer from the human body to the environment via convection and radiation may be unfavorable, as observed in some other semiarid regions worldwide (Heidari et al. 2018). It is relevant to highlight that the use of sun protection implements and rest in the shade could minimize the risk to human health.

It should be mentioned that the choice of only one thermal indicator, WBGT may be a limitation of this study. Although it is a validated and widely applied index, it can be interpreted as a screening tool for thermal stress conditions and its efficiency can be limited when applied to very hot and humid conditions (Budd 2008). Further analysis by means of other indices is strongly recommended in future studies. In addition, the object of this study focused on WBGT exposure, but it is known that potential thermal stress risk should be evaluated alongside assessments regarding social, economic and environmental vulnerabilities.

The use of climate models is also limiting, mentioned in previous studies, since they are endowed with uncertainties (Sampaio and Dias 2014). Climate models, despite their advancement and improvement in recent years, are imperfect representations of nature, and different models may differ in their projections for the future. For example, the maximum WBGT (annual average) 
estimated by HadGEM model presents more extreme projections when compared to other models (http://climatechip.org/your-area-tomorrow) and these differences between the climate models needs to be explored in future studies of health sector. In this study, the use of a regionalized model greatly reduces uncertainties, as it increases the resolution over the area of interest and is, therefore, more refined for local scales. In addition, an inherent limitation in applying climate scenarios is that there is no way to precisely predict the future trajectory of greenhouse gas emissions, which depends on several factors, including political decisions that can affect populations all over the globe.

Considering the health sector, the precautionary principle is used to protect the populations and, in this sense, the RCP 8.5 was used here as a worst scenario and RCP 4.5 as a reference, according to the Paris Agreement's long-term goal, i.e., to keep the increase in global average temperature to below $2{ }^{\circ} \mathrm{C}$ above pre-industrial levels; and to limit the increase to $1.5^{\circ} \mathrm{C}$, since this would substantially reduce the risks and effects of climate change.

This is a pioneer study in Brazil, using data from regionalized climate models to evaluate future risks to human health, presenting potential exposure scenarios to thermal stress in the Brazilian SFRB region from the perspective of the RCP 4.5 and 8.5 scenarios from 1961 and 2099. From a public health point of view, the application of these scenarios, although unrealistic, constitutes a risk management tool, contributing to the adoption of a set of actions and health services that promote prevention, preparedness and response strengthening to climate change impacts, including increases in death tolls from thermal stress conditions.

\section{ACKNOWLEDGMENTS}

We thank Duarte Costa for his valuable contribution and are thankful for the technical support of National Institute of Space Research. This work was supported by the Brazilian Research Network on Global Climate Change (Conselho Nacional de Desenvolvimento Científico e Tecnológico/CNPq $\mathrm{n}^{\mathrm{o}}$ 550022/2014-7 and FINEP/Climate Network 01.13.0353.00).

\section{AUTHOR CONTRIBUTIONS}

B.F.A.O. and S.H. conceived and designed the experiments; B.F.A.O., R.C.F and I.H.S. performed the numerical calculations for suggested experiment; W.L.J. and M.A.P.H. contributed to materials and analysis tools. B.F.A.O., S.H. and W.L.J. wrote the manuscript with input from all authors.

\section{REFERENCES}

A BACIA. 2018. Plano de Recursos Hídricos da Bacia Hidrográfica do Rio São Francisco [Internet]. [cited 2018 Mar 3]. Available from: http://cbhsaofrancisco.org.br/ planoderecursoshidricos/a-bacia/.

ALVALÁ RCS, CUNHA APMA, BRITO SSB, SELUCHI ME, MARENGO JA, MORAES OLL AND CARVALHO MA. 2017. Drought monitoring in the Brazilian Semiarid region. An Acad Bras Cienc 91: e20170209.

AMERICAN ACADEMY OF PEDIATRICS. 2000. Committee on Sports Medicine and Fitness. Pediatrics. Climatic heat stress and the exercising child and adolescent. [Internet]. $2000 \mathrm{Jul}$ [cited 2018 Feb 28]; 106(1 Pt 1): 158-159. Available from: http://www.ncbi.nlm.nih. gov/pubmed/10878169.

BAR-OR O. 1989. Temperature regulation during exercise in children and adolescent. In: Lamb DR and Gisolfi CV (Eds), Perspectives in exercise science and sports medicine: youth, exercise, and sport. Indianapolis: Benchmark Press. 1989, p. 335-368.

BELDING HS AND HATCH TF. 1955. Index for evaluating Heat Stress in Terms of resulting Physiological Strains. Heating Pip Air Cond 27: 129-136.

BITENCOURT DP, RUAS ÁC AND MAIA PA. 2012. Análise da contribuição das variáveis meteorológicas no estresse térmico associada à morte de cortadores de cana-de-açúcar. Cad Saude Publica 28: 65-74.

BOBB JF, PENG RD, BELL ML AND DOMINICI F. 2014. Heat-Related Mortality and Adaptation to Heat in the United States. Environ Health Perspect 122: 811-816.

BUDD GM. 2008. Wet-bulb globe temperature (WBGT)--its history and its limitations. J Sci Med Sport 11: 20-32. 
CHOU SC, LYRA A, MOURÃO C, DERECZYNSKI C, PILOTTO I AND GOMES. 2014a. Assessment of Climate Change over South America under RCP 4.5 and 8.5 Downscaling Scenarios. Am J Clim Chang 3: 512-527.

CHOU SC, LYRA A, MOURÃO C, DERECZYNSKI C, PILOTTO I AND GOMES J. 2014b. Evaluation of the Eta Simulations Nested in Three Global Climate Models. Am J Clim Chang 3: 438-454.

COFFEL ED, HORTON RM AND DE SHERBININ A. 2018. Temperature and humidity-based projections of a rapid rise in global heat stress exposure during the $21^{\text {st }}$ century. Environ Res Lett 13: 14001.

DUNNE JP, STOUFFER RJ AND JOHN JG. 2013. Reductions in labour capacity from heat stress under climate warming. Nat Clim Chang 3: 563-566.

GOMES LHLS, CARNEIRO-JÚNIOR MA AND MARINS JCB. 2013. Respostas termorregulatórias de crianças no exercício em ambiente de calor. Rev Paul Pediatr 31: 104110.

HAVENITH G AND FIALA D. 2015. Thermal Indices and Thermophysiological Modeling for Heat Stress. In: Comprehensive Physiology. Hoboken, NJ, USA: John Wiley \& Sons, Inc., p. 255-302.

HAYMES EM, MCCORMICK RJ AND BUSKIRK ER. 1975. Heat tolerance of exercising lean and obese prepubertal boys. J Appl Physiol 39: 457-461.

HEIDARI H, GOLBABAEI F, SHAMSIPOUR A, RAHIMI FORUSHANI A AND GAEINI A. 2018. Consistency between Sweat Rate and Wet Bulb Globe Temperature for the Assessment of Heat Stress of People Working Outdoor in Arid and Semi-arid Regions. Int J Occup Environ Med 9: $1-9$.

IM E-S, PAL JS AND ELTAHIR EAB. 2017. Deadly heat waves projected in the densely populated agricultural regions of South Asia. Sci Adv 3: e1603322.

INBAR O, MORRIS N, EPSTEIN Y AND GASS G. 2004. Comparison of thermoregulatory responses to exercise in dry heat among prepubertal boys, young adults and older males. Exp Physiol 89: 691-700.

IBGE - INSTITUTO BRASILEIRO DE GEOGRAFIA. 2010. Sinopse do Censo Demográfico. Acessado em 15 de setembro de 2017. Disponível em: http://www.ibge.gov.br/ home/estatistica/populacao/censo2010/sinopse/sinopse tab rm zip.shtm.

IPCC - INTERGOVERNMENTAL PANEL ON CLIMATE CHANGE. 2013. Climate Change: 2013: The Physical Science Basis: Summary for Policymarkers; Intergovernmental Panel on Climate Change, Working Group I Contribution to the IPCC Fifth Assessment Report; IPCC: Geneva, Switzerland, 2013.

IAAF - INTERNATIONAL ASSOCIATION OF ATHLETICS FEDERATIONS. 2013. A Practical Guide International
Association of Athletics Federations Competition Medical Guidelines, 2013.

ISO - INTERNATIONAL ORGANIZATION FOR STANDARDIZATION. 1989. ISO 7243:1989 - Hot environments -- Estimation of the heat stress on working man, based on the WBGT-index (wet bulb globe temperature). Geneva: ISO Standard 7243: International Standards Organization, 1989.

IOANNOU LG, TSOUTSOUBI L, SAMOUTIS G, BOGATAJ LK, KENNY GP AND NYBO L. 2017. Time-motion analysis as a novel approach for evaluating the impact of environmental heat exposure on labor loss in agriculture workers. Temperature 4: 330-340.

KENNEY WL, MORGAN AL, FARQUHAR WB, BROOKS EM, PIERZGA JM AND DERR JA. 1997. Decreased active vasodilator sensitivity in aged skin. Am J Physiol Circ Physiol 272: H1609-14.

KENNY GP, YARDLEY J, BROWN C, SIGAL RJ AND JAY O. 2010. Heat stress in older individuals and patients with common chronic diseases. Can Med Assoc J 182: 1053 1060.

KJELLSTROM T, HOLMER I AND LEMKE B. 2009. Workplace heat stress, health and productivity - an increasing challenge for low and middle-income countries during climate change. Glob Health Action: 2.

LEMKE B AND KJELLSTROM T. 2012. Calculating workplace WBGT from meteorological data: a tool for climate change assessment. Ind Health 50: 267-278.

LILJEGREN JC, CARHART RA, LAWDAY P, TSCHOPP S AND SHARP R. 2008. Modeling the Wet Bulb Globe Temperature Using Standard Meteorological Measurements. J Occup Environ Hyg 5:645-655.

MATSUEDA M. 2011. Predictability of Euro-Russian blocking in summer of 2010. Geophys Res Lett 38(6): https://doi.org/10.1029/2010GL046557.

MAX-PLANCK-INSTITUT FÜR METEOROLOGIE. 2017. Climate Data Operators - CDO [Internet]. 2017 [cited 2017 May 3]. Available from: https://code.mpimet.mpg. de/projects/cdo/files.

NASSIS GP, BRITO J, DVORAK J, CHALABI H AND RACINAIS S. 2015. The association of environmental heat stress with performance: analysis of the 2014 FIFA World Cup Brazil. Br J Sports Med 49: 609-613.

PAL JS AND ELTAHIR EAB. 2016. Future temperature in southwest Asia projected to exceed a threshold for human adaptability. Nat Clim Chang 6: 197-200.

PLANO DE RECURSOS HÍDRICOS DA BACIA HIDROGRÁFICA DO RIO SÃO FRANCISCO. 2015. 2016-2025 - REV1 [Internet]. 2015 [cited 2018 Mar 3]. Available from: http://cbhsaofrancisco.org.br/ planoderecursoshidricos/wp-content/uploads/2015/04/ V1_caract_p1_v2.pdf. 
QGIS DEVELOPMENT TEAM. 2016. QGIS: Geographic Information System Open Source Geospatial Foundation Project [Internet]. 2016. Available from: https://www.qgis. org/pt_BR/site/forusers/download.html.

R CORE TEAM. 2017. R: A language and environment for statistical computing [Internet]. Viena, Austria: R Foundation for Statistical Computing; 2017. Available from: https://www.r-project.org/.

RAHMSTORF S AND COUMOU D. 2011. Increase of extreme events in a warming world. Proc Natl Acad Sci USA 108: 17905-17909.

RÊGO AH. 2012. Os sertões e os desertos: o combate à desertificação e a política externa brasileira. Brasília: FUNAG, $201 \mathrm{p}$.

ROBINE J-M, CHEUNG SLK, LE ROY S, VAN OYEN H, GRIFFITHS C AND MICHEL J-P. 2008. Death toll exceeded 70,000 in Europe during the summer of 2003. C R Biol 331: 171-178.

SAMPAIO G AND DIAS PLS. 2014. Evolução dos Modelos Climáticos e de Previsão de Tempo e Clima. Rev USP $0: 41$.

SCHÄR C. 2016. The worst heat waves to come. Nat Clim Chang 6:128-9.

SHERWOOD SC AND HUBER M. 2010. An adaptability limit to climate change due to heat stress. Proc Natl Acad Sci USA 107: 9552-9555.

SMITH KR, WOODWARD A, LEMKE B, OTTO M, CHANG CJ AND MANCE AA. 2016. The last Summer Olympics? Climate change, health, and work outdoors. Lancet 388 : 642-644.

STOTT PA, STONE DA AND ALLEN MR. 2004. Human contribution to the European heatwave of 2003. Nature 432: 610-614.

VENUGOPAL V, CHINNADURAI J, LUCAS R AND KJELLSTROM T. 2015. Occupational Heat Stress Profiles in Selected Workplaces in India. Int J Environ Res Public Health 13: 89.

YAGLOU CP AND MINARD D. 1957. Control of heat casualties at military training centers. AMA Arch Ind Health 16: 302-316.

\section{APPENDIX}

WBGT is calculated according to the climate variables through a methodology proposed by Liljgreen that considers direct and diffuse components of sunlight. The formulation presented in their work is not simple and needs an iterative process of complex equations. We tried to summarize the methodology process as described below:
Tw is solved iteratively through the following equations (1) and (2):

$$
T w=T a-\frac{\Delta H}{C p} \frac{M_{H 2 O}}{M_{\text {air }}}\left(\frac{C p \rho \partial}{k}\right)^{0.56}\left(\frac{e_{w}-e_{a}}{P-e_{w}}\right)+\frac{\Delta F_{n e t}}{A} \frac{1}{h}
$$$$
\therefore h=\frac{k}{D} 0.281\left(\frac{V D}{\mu}\right)^{0.6}\left(\frac{C_{p} \mu}{k}\right)^{0.44} e_{w}=e_{s a t} T_{w} e_{a}=R H e_{s a t} T_{a}
$$

(2)

$\frac{\Delta F_{\text {net }}}{A}=0.95 \sigma\left[\frac{1}{2}\left(1+\left(0.575 e_{a}^{0.143}\right) T a^{4}-T w^{4}\right]+0.6 S\left[0.2\left(1+\frac{D}{4 L}\right)+0.8\left(\frac{D}{4 L}\right)+0.45\right]\right.$

Tg is solved iteratively in the following equation:

$$
T_{g}^{4}=\frac{1}{2}\left(1+0.575 e_{a}^{0.143}\right) T_{a}^{4}-\frac{h}{0.95 \sigma}\left(T_{g}-T_{a}\right)+\frac{S}{\sigma} 0.525
$$

Where:

\begin{tabular}{|l|}
\hline Tw - natural wet bulb temperature \\
\hline $\mathrm{Ta}$ - air temperature \\
\hline$\Delta \mathrm{H}$ - heat of vaporization \\
\hline $\mathrm{Tg}-$ Globe temperature \\
\hline $\mathrm{M}_{\mathrm{H} 2 \mathrm{O}}$ - molecular weight of water vapor \\
\hline $\mathrm{M}_{\text {air }}$ - molecular weight of air \\
\hline $\mathrm{Cp}$ - specific heat at constant pressure $\rho$ - air density \\
\hline- diffusivity of water vapor in air \\
\hline $\mathrm{k}-$ thermal conductivity of the air \\
\hline $\mathrm{D}-$ wick diameter (psychrometer) \\
\hline $\mathrm{A}$ - surface area of the wick \\
\hline - saturation vapor pressure \\
\hline $\mathrm{RH}-$ relative humidity \\
\hline $\mathrm{P}-$ barometric pressure \\
\hline $\mathrm{V}-$ wind velocity \\
\hline$\mu$ - Air viscosity \\
\hline $\mathrm{h}$ - convective heat transfer coefficient \\
\hline$\sigma-$ Stefan-Boltzmann constant \\
\hline $\mathrm{S}-$ solar radiation \\
\hline $\mathrm{L}-$ wick length \\
\hline
\end{tabular}

The WBGT can be calculated through an excel spreadsheet that contains a number of VBA macros (http://www.climatechip.org/excel-wbgtcalculator) or using HeatStress Package in program R (https://rdrr.io/github/anacv/HeatStress/src/R/ wbgt.Liljegren.R). 